\title{
Post-Treatment Of ISO-1 Attenuates the Expression of MIF And Inflammatory Response to Influenza A (H9N2) Infection on A549 Cells
}

\author{
Chuanxia Hu*, Zhihui Li*, Xiaofang Li, Caihui Zhu and Guimei He \\ School of Life Sciences, East China Normal University, Shanghai, China \\ *Corresponding author: Dr Guimei He, Chuanxia Hu, School of Life Sciences, East China Normal University, China. \\ To Cite This Article: Chuanxia Hu, Zhihui Li, Xiaofang Li, Caihui Zhu, Guimei He, Post-Treatment Of ISO-1 Attenuates the Expression of MIF And \\ Inflammatory Response to Influenza A (H9N2) Infection on A549 Cells. Am J Biomed Sci \& Res. 2021 - 12(2). AJBSR.MS.ID.001724.
}

DOI: 10.34297/AJBSR.2021.12.001724.

Received: 啙 January 28, 2020; Published: 眥 March 01, 2021

\begin{abstract}
H9N2 Avian influenza viruses generally cause mild to moderate infections, and occasionally cause clinical respiratory diseases in humans. Macrophage Migration Inhibitory Factor (MIF), has been evaluated as a pro-inflammatory cytokine, anterior pituitary-derived hormone, and glucocorticoid-induced immune-modulator, associated with inflammatory and immunology reactions of lung diseases. ISO-1[(S, R)-3-(4hydroxyphenyl)-4-5-isoxazole acetic acid methyl ester] is a specific antagonist of macrophage Migration Inhibition Factor (MIF). The question, whether ISO-1-treatment could modulate the inflammatory response induced by H9N2 avian influenza virus, is unclear. This study was undertaken to investigate the chemokine /cytokine response to influenza A infection by post-treatment of ISO-1 on human lung alveolar epithelial cells (A549 cells). The avian influenza virus H9N2 (10-4.46TCID50/100 $\mathrm{\mu l}$ ) was incubated with A549 cells for 24h, then treated with $100 \mathrm{ng} / \mu \mathrm{l}$ ISO-1 and incubated with the A549 cells together at $37^{\circ} \mathrm{C}$ under $5 \% \mathrm{CO} 2$ for $1 \mathrm{~h}$. The cell culture was collected and subjected to RNA extraction. The virus titer, mRNA expression of MIF and other cytokines were analyzed by real-time quantitative-PCR (qRT-PCR). Treatment with ISO-1 after H9N2 infection could attenuate mRNA expression levels of MIF; tumor-necrosis-factor-alpha (TNF- $\alpha$ ), interferon- $\beta$ (IFN- $\beta$ ), nucleus- $\kappa B$ (NF- $\kappa B$ ), leukocyte interleukin (CXCL8), interleukin-6 (IL-6), and influenza M gene significantly, which were up-regulated by H9N2 infection. This study demonstrates that MIF small-molecule antagonist ISO-1 treatment has a significant anti-inflammatory effect on H9N2virus-induced A549 cell inflammation, which further supports the investigation of ISO-1 to address the inflammatory disease induced by the avian influenza viruses.
\end{abstract}

Keywords: ISO-1, H9N2, MIF, Cytokines/Chemokines, Inflammatory Response, Treatment, Influenza Viruses, Quantitative-PCR, Mammals, Vaccine, Pathogenicity, Respiratory Droplet, Sepsis, Arthritis, Diabetes, Lung Injury

\section{Introduction}

The H9N2 subtype of influenza viruses have continues to be the most abundant influenza viruses isolated from chickens in China. Multiple studies show that the H9N2 viruses have undergone continuous and rapid evolution as well as wide re-assortment with other subtypes of avian influenza viruses, such as the H9N2 viruses might be the donors of the "internal" genes of the lethal H5N1 viruses, H5N6, H10N8, and H7N9 [1-6]. Furthermore, the pressure of vaccine and natural immunity may contribute to substantial virus evolution, and the rapid evolution also leads to enhanced pathogenicity for the virus in mammals and poultry [7]. Mouseadapted H9N2 influenza viruses could replicate efficiently and be transmitted among mice through both contact and respiratory droplet routes [8]. Events show that H9N2 influenza viruses are capable of infecting mammals including humans from 1999 [1]. Influenza virus infections lead to the interaction of virus and host immune responses including excessive inflammatory responses in the form of cytokine storm. The increased expression of proinflammatory cytokines has an important role both in the adaptive 
and innate immune responses [9]. Macrophage Migration Inhibitory Factor (MIF) is known to be an important regulator of the innate and adaptive immune systems and inflammatory responses, which has been implicated in several inflammatory diseases, such as sepsis, arthritis, diabetes, and lung injury [10].

MIF is produced by a variety of inflammatory and immune cells; its expression is regulated by several different stimuli such as LPS or virus infection [11]. Recent findings demonstrated that MIF modulates inflammatory and immunological responses which functions as an initiator by regulating production of several cytokines, including tumor necrosis factor (TNF-a), interleukin (IL)-1 and IL-6 [12]. As such, a promising therapeutic approach to diminish pathological immune inflammation is to inhibit the production and/or biological activity of MIF. There are well-documented that anti-MIF antibody could attenuate the inflammatory cascade in sepsis and other diseases [13]. ISO$1[(\mathrm{~S}, \quad \mathrm{R})-3-(4-h y d r o x y p h e n y l)-4,5$-dihydro-5-isoxazole acetic acid methyl ester)], was synthesized from 1997 as a non-toxic, specific antagonist of MIF [14]. ISO-1 inhibits TNF- $\alpha$ release from macrophages isolated from LPS treated wild type mice but has no effect on cytokine release from MIF deficient macrophages [13]. It is well documented that modulation of inflammatory response through treatment with an anti-inflammatory agent can effectively reduce clinical complications and optimize recovery in virusinfected patients $[12,15]$. In this study, we hypothesis that ISO-1 could regulate the inflammatory responses on A549 cells induced by the H9N2 virus infection, which might provide mechanistic insights into the anti-inflammatory efficacy of ISO-1.

\section{Methods and Materials}

\section{Virus}

The avian influenza virus A/mallard/Jiangxi/39/2011 (H9N2) was isolated from the wild duck from Poyang Lake in Jiangxi province of China in 2011[16]. Phylogenetic analysis showed that the strain clustered with the 2009 human H9N2 viruses (HK/35820/2009 and HK/33928/2009), and the virus was capable of inducing pneumonia in BALB/c mice. Sequences of the H9N2 genome can be acquired from the Genebank (National Center for Biotechnology Information, Bethesda, MD) [16]. The virus was enriched in 10-day-old Specific Pathogen Free (SPF) chicken embryos (Beijing Laboratory Animal Research Center, China) and incubated at $37^{\circ} \mathrm{C}$ for 72 hours. The allantoic fluid was collected and stored in a refrigerator at $-80^{\circ} \mathrm{C}$ for further use. The $50 \%$ tissue culture infection dose (TCID50) was tested on the human alveolar epithelial cell line A549 and the virus titer (calculated by Karber Method) was 10-6.46/100 $\mu$ l.

\section{Cells and reagents}

The human alveolar epithelial cell line A549 was purchased from the Cell Bank of Chinese Academy of Science (China). Cells were cultured in Dulbecco's Modified Eagle Medium (DMEM, HyClone, USA), with 10\% Fetal Bovine Serum (FBS, Gibco, USA) and $1 \%$ penicillin-streptomycin (Gibco, USA). A549 cells were grown in T-25 tissue culture flasks (Corning, USA) in a humidified incubator (Thermo, USA) at $37^{\circ} \mathrm{C}$ with $5 \%$ CO2. ISO-1([(S, R)-3-(4hydroxyphenyl)-4, 5-dihydro-5-isoxazole acetic acid methyl ester]) was purchased from the Merck-Mellipore, USA. The stock solution of ISO-1 (1000ng/ $\mu \mathrm{l})$ was diluted with $1 \%$ Dimethyl sulfoxide (DMSO) before use and stored in the refrigerator at $-20^{\circ} \mathrm{C}$.

\section{Dose-response and time-course effects of ISO-1 on A549 cells}

The dose-response and time-course effects of ISO-1 acted on the A549 cells were tested. In brief, the A549 cells were grown to confluence, different concentrations of ISO-1 (10, 30, 100, 200, and $400 \mathrm{ng} / \mu \mathrm{l}$ ) were added and incubated with the cultured A549 cells in triplicate, and then the cell culture were harvested at $0.5 \mathrm{~h}, 1 \mathrm{~h}, 4 \mathrm{~h}$, $6 \mathrm{~h}, 16 \mathrm{~h}, 21 \mathrm{~h}, 24 \mathrm{~h}$ after the incubation. The total cellular RNA was extracted according to a previous protocol. MIF and other cytokines expression were analyzed by real-time quantitative-PCR (qRT-PCR).

\section{Effects of ISO-1 on A549 cells post-H9N2 infection}

Based on the above results, ISO-1 in a concentration of 100ng/ $\mu \mathrm{l}$ and incubation with $\mathrm{A} 549$ cells for $1 \mathrm{~h}$ were used to investigate the effect of ISO-1 on A549 cells for post-infection of H9N2 virus. For virus infection, A549 cells were reached approximately $90 \%$ confluence, 10-4.46TCI50/100 $\mu \mathrm{l}$ H9N2 viruses or the same volume of non-infectious virus were inoculated and incubated with cells at $37^{\circ} \mathrm{C}$ under $5 \% \mathrm{CO} 2$ for $24 \mathrm{~h}$. Then $100 \mathrm{ng} / \mu \mathrm{l}$ ISO- 1 were added after virus incubation. After $1 \mathrm{~h}$, the cell culture was harvested. The TCID50 of cell culture supernatants were determined to quantify the influenza virus titer. The total cellular RNA was extracted according to a previously described protocol, and MIF and other cytokines expression were analyzed by real-time quantitative-PCR (qRT-PCR). 1\% DMSO group and H9N2 infection group were used to as two control groups.

\section{Relative qRT-PCR analysis}

The gene expression of MIF, IL-6, TNF- $\alpha$, IFN- $\beta$, CXCL-8, NF-K $\beta$ and H9N2 $M$ were assessed by the relative quantitative real-time PCR (qRT-PCR), performed with the Applied Biosystems7300 system (Life Technologies, Carlsbad, CA). The qRT-PCR primers were designed using software Primer Premier 5.0 (Premier, Canada), and the detailed information was shown in Table 1. The total RNA was extracted from the supernatant and cytoplasm according to the RNeasy Mini Kit (QIAGEN). The first-strand complementary DNA was synthetized following the instructions of the Invitrogen Transcription SuperScriptTM III RT Kit (Invitrogen, US). The qRTPCRs were carried out in a total volume of $20 \mu$ l containing $10 \mu \mathrm{l}$ SYBR Premix Ex Taq $(2 \times), 0.4 \mu \mathrm{l}$ forward primer, $0.4 \mu \mathrm{l}$ reverse primer, $0.4 \mu \mathrm{l}$ ROX reference dye $(50 \times), 2 \mu \mathrm{l}$ cDNA and $6.8 \mu \mathrm{l} \mathrm{H} 20$ by 
SYBR Premix Ex Taq RR420A-Tli RNase H Plus (TAKARA Clontech, Dalian). The reaction was performed as follows: 30 s for $95^{\circ} \mathrm{C}, 40$ cycles of $95^{\circ} \mathrm{C}$ for $5 \mathrm{~s}, 60^{\circ} \mathrm{C}$ for $31 \mathrm{~s}$, followed by a dissociation stage. All quantifications were normalized to the housekeeping GAPDH gene, which showed a very stable expression in A549 cells. Each sample was amplified in fourfold, and all data was analyzed using Sequence Detector Systems software (Applied Biosystems, USA). Fold changes in expression were calculated according to the $2-\Delta \Delta \mathrm{Ct}$ method, in which the $\Delta \mathrm{Ct}$ values were compared with the value of the control groups.

Table 1: Primers sequence for $\mathrm{qRT}$-PCR.

\begin{tabular}{|c|}
\hline Target gene Direction Sequence \\
\hline IL-6 Forward 5'-TCCACAAGCGCCTTCGGTCCAG-3' \\
\hline Reverse 5'-CTCAGGGCTGAGATGCCGTCG-3' \\
\hline TNF- $\alpha$ Forward 5'-ATGAGCACAGAAAGCATGATC-3' \\
\hline Reverse 5'-TACAGGCTTGTCACTCGAATT-3' \\
\hline IFN- $\beta$ Forward 5'-TGGGAGGCTTGAATACTGCCTCCA-3' \\
\hline Reverse 5'-TCCTTGGCCTTCAGGTAATGCAGA-3' \\
\hline CXCL8 Forward 5'-GTGTGAAGGTGCAGTTTTGCCAAGG-3' \\
\hline Reverse 5'-GCACCCAGTTTTCCTTGGGGTCC-3' \\
\hline M gene Forward 5'-ATGAGYCTTYTAACCGGGTCGAAACG3' \\
\hline Reverse 5'TGGACAAANCGTCTACGCTGCAG3' \\
\hline NF-K $\beta$ Forward 5'GGAAAGATTTCTGGCTCAGCTC3' \\
\hline Reverse 5'AGTGGCTTTCTCCTCACTAAGACC3' \\
\hline MIF Forward 5'TCCTTCTGCCATGCCGA3' \\
\hline Reverse 5'TGCGGCTCTTAGGCGAAGGT3' \\
\hline GAPDH Forward 5'ATGACCTTGCCCACAGCC3' \\
\hline Reverse 5'CCCATCACCATCTTCCAG3' \\
\hline
\end{tabular}

\section{Statistical analysis}

All data are expressed as means \pm Standard Deviation (SD). Statistical analysis was performed using SPSS for Windows version 19.0 (SPSS Inc, USA) and Sigma plot version 12.5 (Systat Software, US). The one-way analysis of variance (ANOVA) followed by a posthoc Tukey test or unpaired two-tailed t-test was used to evaluate the statistical significance of differences between two groups. In all statistical analyses, significance was accepted at $\mathrm{P}<0.05$.

\section{Results nd Discussion}

\section{Effects on MIF expression after H9N2 influenza infection}

MIF has been well characterized as a mediator of numerous pulmonary inflammatory disease [12], and the elevated concentrations of MIF may highly positively link to the disease's severity. The present study reveals that MIF reached a peak $24 \mathrm{~h}$ after H9N2 influenza virus infection (Figure 1), and then decreased after that. The result is in line with previous reports showing that the MIF mRNA and protein levels were increased in the lungs of H5N1 influenza virus infection [16].

\section{Optimization of the time and concentration of ISO-1}

ISO-1, as a small molecule antagonist of MIF, can inhibited its activity [14]. To determine the dose-response and time-course effects of ISO-1 on A549 cells, firstly different ISO-1 concentrations ranging from 10 to $400 \mathrm{ng} / \mu \mathrm{l}$ were used according to the previous studies $[14,18-20]$. We found that ISO-1 treatment leaded to reduce the expression of MIF, especially the dosage of $100 \mathrm{ng} / \mu \mathrm{l}$ of ISO-1, the expression level of MIF was significantly reduced about 6 times compared with that of the control group $(\mathrm{p}<0.05)$ (Figure $2 \mathrm{~A}$ ). Then, A549 cells were treated with $100 \mathrm{ng} / \mu \mathrm{l}$ ISO-1 and incubated for $0.5 \mathrm{~h}, 1 \mathrm{~h}, 4 \mathrm{~h}, 6 \mathrm{~h}, 16 \mathrm{~h}, 21 \mathrm{~h}$, and $24 \mathrm{~h}$ respectively. Interestingly, a significant reduction in the expression of MIF were only observed at the early stage of the incubation from 0.5 to $4 \mathrm{~h}$ and could not be detected at the later time points (Figure 2B). We speculate that with the incubation time prolonged, ISO-1 might lose the ability to attenuate the mRNA expression of MIF gradually. According to the results, it was identified that intracellular MIF expression was inhibited by ISO-1, but the expression of MIF in A549 cell was not in a time-dependent and dose-dependent manner. We select the $100 \mathrm{ng} / \mu \mathrm{l}$ ISO-1 and an hour incubation time as the optimization of the time and concentration of ISO-1 in these following studies.

\section{Effects of ISO-1 on the expression of MIF after H9N2 virus infection}

To determine whether ISO-1 could inhibit MIF expression on A549 cells post-H9N2 influenza virus infection, we evaluated the 
expression of MIF at mRNA levels in A549 cells. Compared with the two non-infected control groups, H9N2-challenged group had a higher MIF expression level, while ISO-1 treatment could significantly [17] inhibit the MIF expression in ISO-1-treatedinfected group and the ISO-1-treated control group (Figure 3). In addition, we also tested the effect of ISO-1 pre-treatment on the expression of MIF after H9N2 virus infection but found only slightly decrease of MIF expression (data no shown). These results confirmed that post-treatment with ISO-1 in H9N2 infected cells could significantly reduce the MIF expression levels after H9N2 virus infection.

\section{MIF}

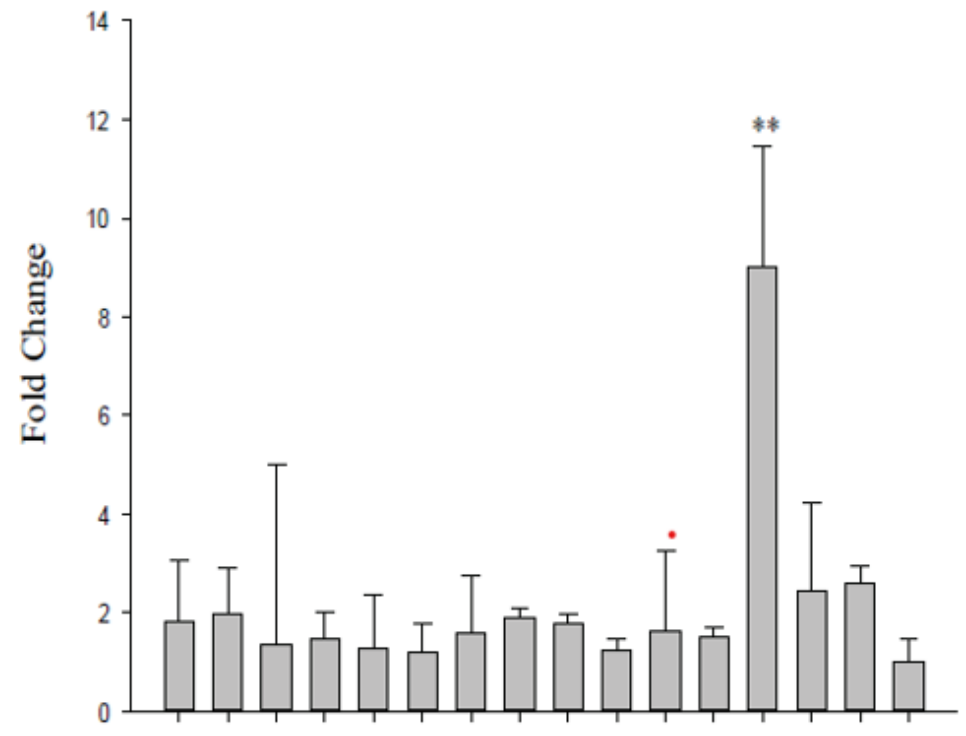

1h $2 \mathrm{~h} \quad 4 \mathrm{~h} \quad 6 \mathrm{~h} \quad 8 \mathrm{~h} \quad 10 \mathrm{~h} 12 \mathrm{~h}$ 14h $16 \mathrm{~h} 18 \mathrm{~h}$ 20h $22 \mathrm{~h} 24 \mathrm{~h} 36 \mathrm{~h} 48 \mathrm{~h}$ Contro

Time point post $\mathrm{H} 9 \mathrm{~N} 2$ infection(h)

Figure 1: Relative MIF mRNA expression levels in A549 cells. (A) Relative MIF mRNA levels after H9N2-AIV infection over a range of time (from 2 to $48 \mathrm{~h}$ ) were determined by qRT-PCR. The gene expression was normalized to $\beta$-actin, and data were calculated using the 2 - $\triangle \triangle \mathrm{Ct}$ method in which all $-\triangle \mathrm{Ct}$ values were compared with the value obtained from uninfected control cells. ${ }^{* *} \mathrm{P}<0.01$, representative results of three independent experiments are shown.
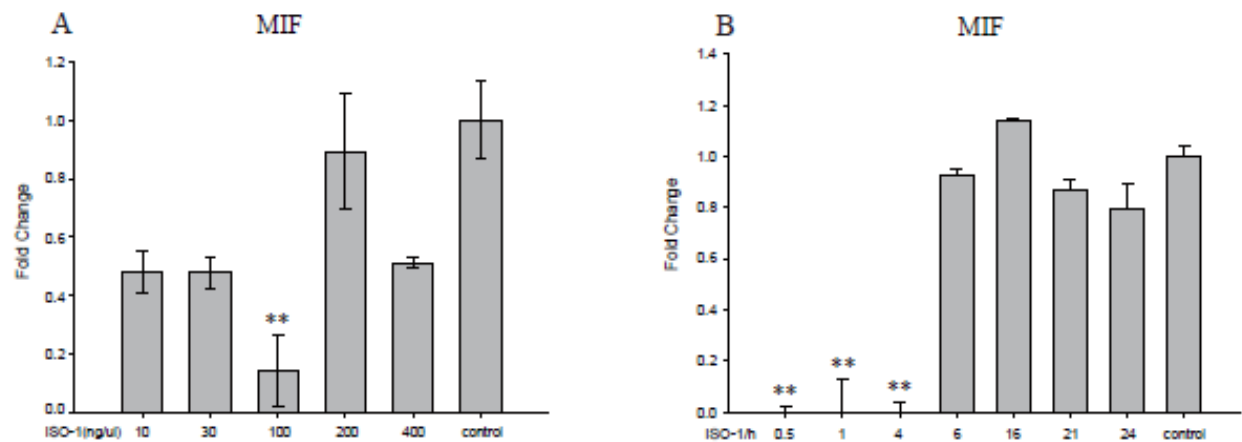

Figure 2: Dose-response and time-course effects of ISO-1 on A549 cells. A549 cells were treated with ISO-1 in different concentrations and time. (A) ISO-1 concentrations ranging from 10 to $400 \mathrm{ng} / \mu \mathrm{l}$, cells were collected at $0.5 \mathrm{~h}$ after infection. (B) ISO-1 challenged A549 cells in $100 \mathrm{ng} / \mu \mathrm{l}$ and incubated for $0.5 \mathrm{~h}, 1 \mathrm{~h}, 4 \mathrm{~h}, 6 \mathrm{~h}, 21 \mathrm{~h}, 24 \mathrm{~h}$ respectively. MIF genes were determined in quadruplicate by qRT-PCR. The gene expression levels were normalized to $\beta$-actin. Data were calculated using the $2-\triangle \triangle \mathrm{Ct}$ method. ${ }^{* *} \mathrm{P}<0.01$, representative results of three independent experiments are shown. 
MIF

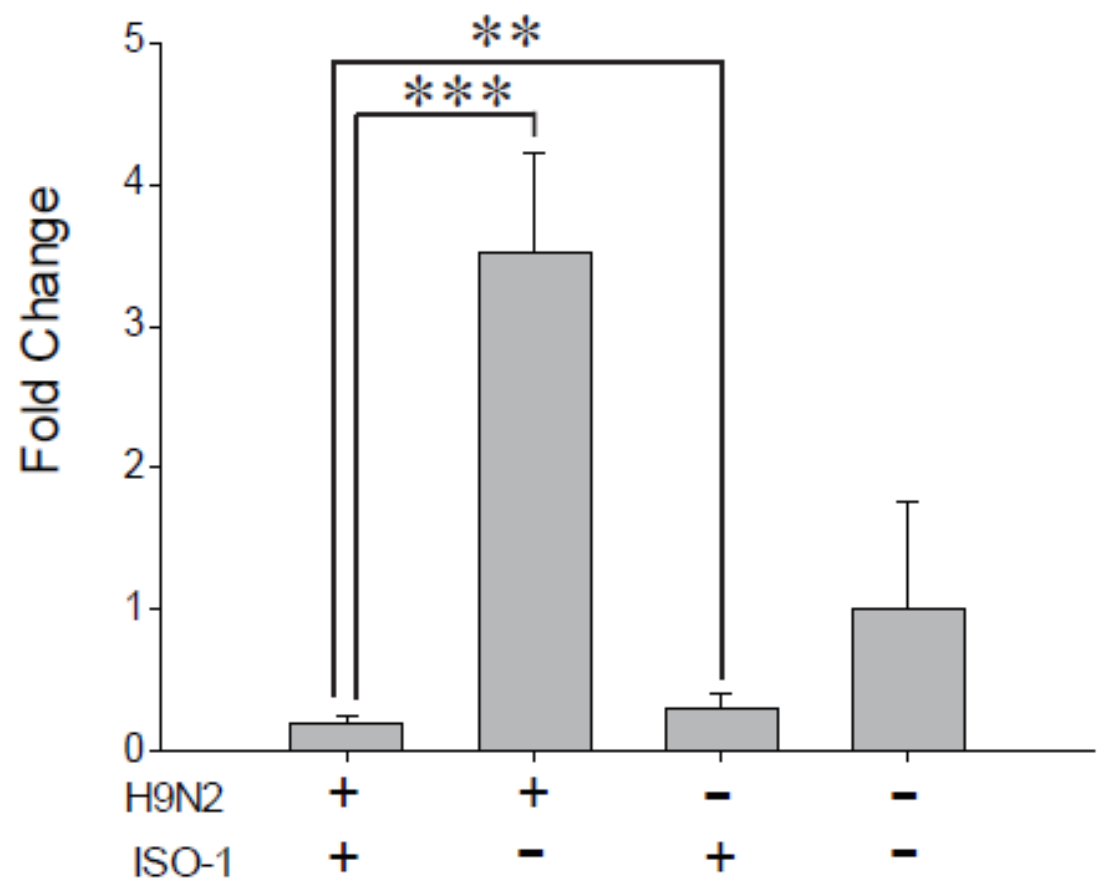

Figure 3: Effect of post-treatment of ISO-1 on MIF expression after H9N2 infection. A549 cells were exposed to H9N2 and then challenged with ISO-1(100ng/ $\mathrm{Ll}, 1 \mathrm{~h})$. MIF expression levels were normalized to $\beta$-actin and expressed as fold increases relative to control groups. ${ }^{* *} \mathrm{P}<0.01$, ${ }^{* * *} \mathrm{P}<0.001$, data were calculated using the $2-\triangle \triangle \mathrm{Ct}$ method. Representative results of three independent experiments are shown.
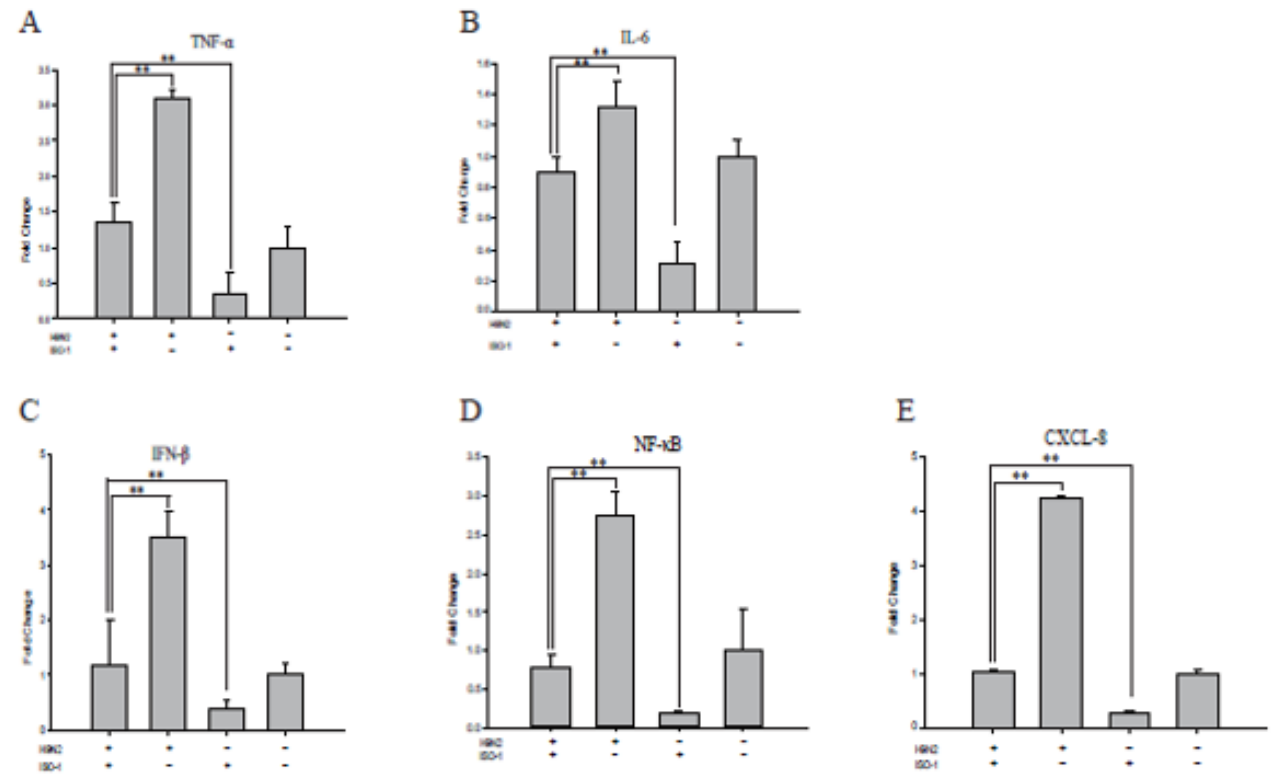

Figure 4: Effect of post-treatment of ISO-1 on cytokines expression after H9N2 infection. A549 cells were exposed to H9N2 and then challenged with ISO-1(100ng/ul, 1h). The genes TNF-a, IL-6, IFN-b, NF-kB, and CXCL8 (Figure 4A-E) mRNA expression levels were normalized to $\beta$-actin and expressed as fold increases relative to control groups. ${ }^{* *} \mathrm{P}<0.01$. Data were calculated using the $2-\triangle \triangle \mathrm{Ct}$ method. 

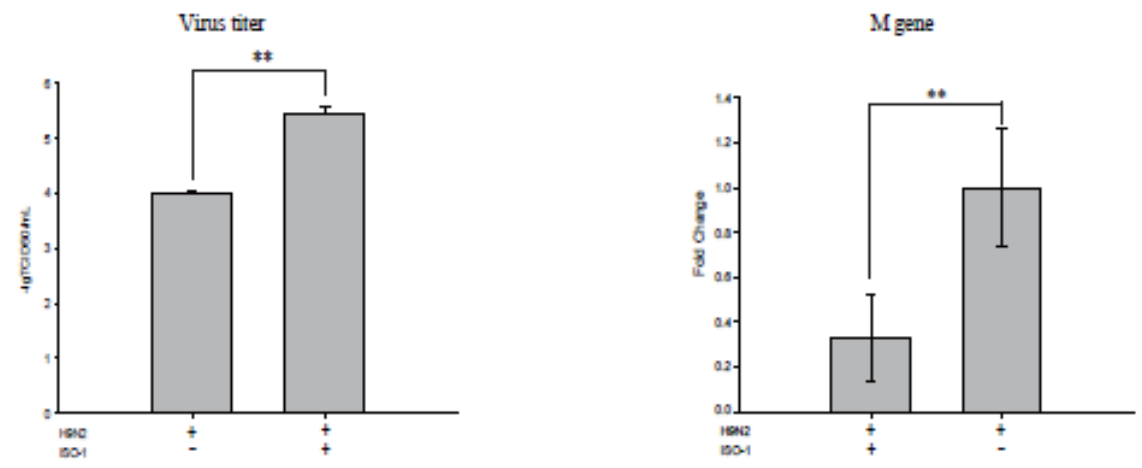

Figure 5: Effect of post-treatment of ISO-1 on viral replication after H9N2 infection. A549 cells were exposed to H9N2 and then challenged with ISO-1(100 ng/ $\mu \mathrm{l}, 1 \mathrm{~h})$. (A) Virus titer of H9N2 was measured by TCID50, calculated by Reed-Muench method. (B) M gene expressions were determined in quadruplicate by qRT-PCR. The gene expression levels were normalized to $\beta$-actin. Data were calculated using the $2-\triangle \triangle \mathrm{Ct}$ method. ${ }^{* *} \mathrm{P}<0.01$, representative results of three independent experiments are shown.

\section{Effects of ISO-1 on cells inflammation induced by H9N2 virus}

MIF plays an important role in the immune inflammatory response, we hypothesize that ISO-1 as a specific antagonist of MIF tautomerase, could reduce the inflammation of H9N2 infected A549 cells. In this test, we analyzed the mRNA expression levels for cytokines by qRT-PCR. The results showed a significant rise in mRNA expression of these cytokines/chemokines on H9N2 viruses infected cells. The change patterns of these cytokine expression levels in the ISO-1 treated-infected group were like that of the expression levels of MIF, which were significantly lower than those in the virus challenge group, such as tumor necrosis factor (TNF)- $\alpha$, interleukin (IL)-6, human interferon- $\beta$ (IFN $\beta$ ), nuclear factor-kappaB (NF-kappaB), Interleukin-8/CXCL8 (IL-8) decreased about 2-fold to 4-fold separately (Figure 4A-4E). The data from our investigation indicates that antagonism of MIF could suppress the increased expression of cytokines induced by H9N2 virus in-vitro.

\section{Effect of ISO-1 on viral replication after H9N2 virus infection}

Seeing the downregulation of cytokines on treatment of ISO1 , we then focused our attention on comparing the virus titer of H9N2 and M gene expression in the two infected groups with or without ISO-1 treatment. Figure 5B showed that the expression levels of M gene were significantly decreased after ISO-1 treatment. Accordingly, we reasoned that ISO-1 inhibition of MIF might suppress the virus replication in A549. We compared the virus titer between the two groups, found that the virus titer was also lower in the ISO-1 treated group than the virus control group (Figure $5 \mathrm{~A}$ ). From these results, we deduced that ISO-1 treatment might affect the viral levels on H9N2 virus infection. Collectively, these results provide evidence that ISO-1 could inhibit the secretion and biological function of MIF. MIF modulate many signaling pathways and inflammation of H9N2 virus infected cells via regulating cytokines expression, such as TNF- $\alpha$, IL-6, IFN $\beta$, NF-kappaB, and CXCL8. It will be important to perform clinical studies with MIF targeting agents, ISO-1, to, fully define a role of MIF in H9N2 infected A549 cells, inhibit the production and biological activity of MIF, as well as suppress production of other cytokines, and diminish pathological inflammation.

Consequently, decreased production of proinflammatory cytokines and virus titers generate a less deleterious environment in the A549 cells.

\section{Conclusion}

We verify that treatment with ISO-1 post-infection with H9N2 could attenuate the mRNA expression levels of MIF, TNF- $\alpha$, IFN- $\beta$, NF- $\kappa B$, IL-6, and CXCL-8, compared with the infected A549 cells without treatment with ISO-1. Meanwhile, H9N2 virus replication and $\mathrm{M}$ gene expression decreased when treated with ISO-1. The findings from this study provide mechanistic insights into the antiinflammatory efficacy of ISO-1 and demonstrated for the first time the regulatory potential of ISO-1 at the level of A549 cytoplasm, which can preserve the target cell from H9N2 influenza virus attack. It is suggested that ISO-1 treatment down-regulates the immune response of H9N2 avian influenza virus infected A549 cells, and attenuate virus propagation. Strategies seeking to protect A549 cells from influenza virus infection might benefit from the administration of ISO-1. We believe these studies provide a strong rational for additional working seeking to identify the potential role of ISO-1 in the pathogenesis of ALI and justify examination of the potential therapeutic benefits of ISO-1 administration for reversing and/or preventing these disorders.

There are several limitations in the current study. We were unable to demonstrate a significant effect of ISO-1 on indicators of lung injury or inflammation of mouse model induced by influenza virus, although A549 cellular cytokines response were affected. It 
will be important to perform clinical studies with MIF-targeting agents to fully define a role for MIF in avian influenza virus infected inflammation. Unfortunately, efficacy similar approaches not known because of the lack of clinical studies with specific inhibitors of these cytokines. This is in line with our study indicating that inhibition of MIF in the target cell may promote the local counterregulatory pathways that ensure the resolution of inflammation and protect cell damage. ISO-1 seems worthy of being considered as a candidate drug in the development of new therapeutic strategies for the treatment of ALI and relevant disease.

\section{Acknowledgement}

This work was funded by the National Natural Science Foundation of China (31402163), National Key Plan for Scientific Research and Development of China (2016YFD0500300), and Shanghai Wildlife Epidemic Disease Monitoring Program.

\section{Declaration of Conflict of Interest: None}

${ }^{*}$ Contributed equally to this work.

\section{References}

1. Saito T, Lim W, Tashiro M (2004) Attenuation of a human H9N2 influenza virus in mammalian host by reassortment with an avian influenza virus. ARCH VIROL 149(7): 1397-1407.

2. Liu M, Li X, Yuan H, Zhou J, Wu J, et al. (2015) Genetic diversity of avian influenza a (h10n8) virus in live poultry markets and its association with human infections in china. Sci Rep 5: 7632.

3. Hao XL, Wang JJ, Hu J, Lu XL, Gao Z, et al. (2017) Internal Gene Cassette from a Genotype S H9N2 Avian Influenza Virus Attenuates the Pathogenicity of H5 Viruses in Chickens and Mice. FRONT MICROBIOL 8: 1978.

4. Lu J, Raghwani J, Wu J, Pryce R, Bowden TA, et al. (2017) Molecular evolution, diversity, and adaptation of influenza A H7N9 viruses in China. Emerg Infect Dis 24(10): 1795-1805.

5. Hou XQ, Gao YW, Yang ST, Wang CY, Ma ZY, et al. (2009) Role of macrophage migration inhibitory factor in influenza H5N1 virus pneumonia. Acta Virol 53(4): 225-231.

6. Zhang Z, Rui L, Jiang L, Xiong C, Chen Y, et al. (2016) The complexity of human infected AIV H5N6 isolated from China. BMC Infect Dis 16: 600.
7. Algarib S, Almesilaty AAL, (2016) Low pathogenic avian influenza H9N2: world-wide distribution. World Poultry Sci J 72(1): 125-136.

8. Rahimirad S, Alizadeh A, Alizadeh E, Hosseini SM (2016) The avian influenza H9N2 at avian-human interface: A possible risk for the future pandemics. J Res Med Sci 21: 51.

9. Khare D, Godbole NM, Pawar SD, Mohan Vishwa, Pandey G, et al. (2013) Calcitriol [1, 25[OH]2 D3] pre- and post-treatment suppresses inflammatory response to influenza A (H1N1) infection in human lung A549 epithelial cells. Eur J Nutr 52(4): 1405-1415.

10. Zhang Y, Zhang B, Xu DQ Li WP, Xu M, et al. (2011) Tanshinone IIA attenuates seawater aspiration-induced lung injury by inhibiting macrophage migration inhibitory factor. Biol Pharm Bull 34(7): 10521057.

11. Hoi AY, Iskander MN, Morand EF, (2007) Macrophage migration inhibitory factor: a therapeutic target across inflammatory diseases. Inflamm Allergy Drug Targets 6(3): 183-190.

12. Hoi AY, Hickey MJ, Hall P, Yamana J, Sullivan KM, et al. (2006) Macrophage migration inhibitory factor deficiency attenuates macrophage recruitment, glomerulonephritis, and lethality in MRL/lpr mice. J Immunol 177(8): 5687.

13. Nishio Y, Nishihira J, Ishibashi T, Kato H, Minami A (2002) Role of macrophage migration inhibitory factor (MIF) in peripheral nerve regeneration: anti-MIF antibody induces delay of nerve regeneration and the apoptosis of Schwann cells. Mol Med 8(9): 509-520.

14. Al Abed, Y, Dabideen D, Aljabari B, Valster A, Messmer D, et al. (2005) ISO-1 binding to the tautomerase active site of MIF inhibits its proinflammatory activity and increases survival in severe sepsis. J Biol Chem 280(44): 36541-36544.

15. Ginde AA, Mansbach JM, Jr CC (2009) Association between serum 25-hydroxyvitamin D level and upper respiratory tract infection in the Third National Health and Nutrition Examination Survey. Arch Inter Med 169(4): 384-390.

16. Zhu G, Wang R, Xuan F, Daszak P, Anthony Sj, et al. (2013) Characterization of recombinant H9N2 influenza viruses isolated from wild ducks in China. Vet Microbiol 166(3-4): 327-336.

17. Baugh JA and Bucala R (2003) Macrophage migration inhibitory factor. Crit Care Med 7: 153-164. 